\title{
VENCER O MORIR. MITOLOGÍA Y SOCIEDAD ENTRE LOS CHOLES
}

José Alejos García

Centro de Estudios Mayas

\section{Introducción}

La historia contemporánea de los choles de la Sierra Norte de Chiapas es un proceso dinámico, lleno de acontecimientos y cambios radicales, que el grupo guarda en su memoria colectiva y recrea cotidianamente en su discursividad social. Uno de los asuntos que los campesinos choles conservan muy vivo en sus recuerdos es la reforma agraria de los años treinta de este siglo, sin duda por la trascendencia de los cambios ocurridos en aquel entonces y por su importancia actual. Sobre esos acontecimientos, de los que fueron testigos los ancianos que aún viven, existe un género discursivo agrarista, que la gente actualiza al contar sus testimonios, anécdotas y otras formas narrativas (Alejos, 1994).

Acerca de aquel pasado también existen numerosas fuentes documentales de primera mano, particularmente en los archivos municipales de la región, que conservan libros y oficios de la administración política local y nacional, al igual que la correspondencia entre el ayuntamiento y los vecinos del municipio, sobre todo la que se dio entre éste y los dueños y administradores de las antiguas fincas cafetaleras.

En este artículo me propongo hacer una lectura de ambas fuentes documentales, la tradición oral y los documentos de archivo, para examinar las relaciones entre la sociedad indígena y su pensamiento mitológico. El interés está puesto en la relación entre el pensamiento y la acción, en la función de los mitos como paradigmas para la conducta social. Con base en los materiales analizados, planteo que los choles poseen mensajes mitológicos que emplean en determinadas circunstancias para interpretar su historia y para conducirse en sociedad, y que en ambos casos los mitos les proporcionan imágenes positivas, de lu- 
cha y de triunfo, no trágicas y fatalistas, como las que suelen atribuirse a los grupos mayas.

No se pretende argumentar que se trate de una relación causal, directa o simple entre pensamiento y conducta, pues como bien ha señalado Lévi-Strauss, éstas son relaciones de naturaleza dialéctica, que pueden ser inversas, que no ocurren en forma de re-presentación (1983: 169). Pero las relaciones efectivamente existen y el buscar los nexos que comunican a ambas dimensiones puede conducirnos a la comprensión del sentido social del mito.

\section{Mitológicas}

Los mitos, así como otras formas narrativas tradicionales, contienen mensajes ideológico-culturales, que funcionan como modelos paradigmáticos para la acción social, para la conducta real de los miembros de la cultura a la que pertenecen. En términos de Bajtín, puede decirse que existe un nivel dialógico en el que la gente habla con sus mitos, escucha y responde a las palabras de sus héroes, actualizando de esa manera ideas, valores, ejemplos. Es en ese nivel donde es posible identificar rasgos distintivos de un ethos o personalidad característica de la cultura en un momento dado.

Una fuente documental de extraordinario valor para el estudio de la mitología maya es el Popol Vuh, escrito por los quichés de Guatemala en el siglo xvi. En él se narran los mitos de creación de la humanidad y de la fundación de este pueblo, así como su desarrollo histórico hasta la llegada de los españoles. Es notable que en todos los relatos contenidos en el texto se den situaciones de lucha, de conflictos y agresiones extremas que van hasta la muerte, como hechos de un proceso orientado al triunfo de valores morales. Así vemos cómo, desde un inicio, los primeros hombres de madera, "fueron aniquilados, destruidos y deshechos... recibieron la muerte" por no pensar ni hablar con su creador:

Xecotcovach llegó y les vació los ojos; Camalotz vino a cortarles la cabeza; y vino Cotzbalam y les devoró las carnes. El Tucumbalam llegó también y les quebró y magulló los huesos y los nervios, les molió y desmoronó los huesos (1982: 30-31).

La razón para acabar con los hombres de madera es que moralmente no era bueno que existieran sobre la tierra si no veneraban ni recono- 
cían a su creador, y la manera terrible en que fueron destruidos corresponde a su falta.

Luego encontramos otro relato acerca de dos muchachos llamados Hunahpú e Ixbalanqué, quienes "eran dioses verdaderamente" y llegan a la tierra con la misión de vencer a Vucub-Caquix y a sus dos hijos, seres muy poderosos caracterizados por su soberbia, su vanidad y por pretender ser divinidades. Después de varias hazañas, estos héroes logran derrotar a aquéllos, dándoles muerte mediante el engaño y la astucia; al padre, sacándole los dientes y reventándole los ojos (p. 38); a un hijo, derribándole una montaña encima; mientras que al otro, "atáronle los brazos detrás de la espalda y le ataron también el cuello y los pies juntos. Luego lo botaron al suelo, y allí mismo lo enterraron" (p. 47).

En los relatos posteriores, dichos héroes realizan otros actos extraordinarios al derrotar a los señores del inframundo, de Xibalbá, que habían dado muerte a sus padres. Al final, ambos héroes se convierten en el Sol y la Luna, invocando en su despedida la memoria de sus padres: "Nosotros somos los vengadores de vuestra muerte, de las penas y dolores que os causaron [los de Xibalbá]" (p. 102).

Las hazañas de los cuatro primeros hombres fundadores del pueblo quiché también están llenas de luchas, derrotas y triunfos, como lo ilustra el robo del fuego por los cakchiqueles, quienes "no quisieron entregarse como vencidos, de la manera como fueron vencidas las demás tribus cuando ofrecieron su pecho y su sobaco para que se los abrieran", pues así lo había ordenado su dios Tohil (p. 115). Estos mismos héroes protagonizaron "la matanza de las tribus" (p. 128) para sacrificarlas a sus dioses, así como las cruentas guerras que se sucedieron hasta la rendición de todas las tribus enemigas (p. 139).

Los conflictos, guerras y victorias continúan hasta el final del libro, pues con la llegada de los conquistadores hispanos se inicia una nueva era de lucha.

Este carácter bélico de los antiguos mayas lo destacó Ruz Lhuillier en su obra sobre las costumbres funerarias, donde observa que, en efecto, "la lucha y la muerte son los temas constantes de la mitología" contenida en el Popol Vuh (1991: 51). Eso mismo ha observado Ochiai (1986) en un estudio semiótico sobre los mitos de los héroes gemelos en el Popol Vuh. Él identifica dos "mitos de combate", a los que trata de encontrar los mensajes inmanentes, sus paradigmas. Citando a Edmonson, Ochiai nos dice que los mitos de combate suman 3810 líneas, de las 8580 que componen todo el libro (p. 84), lo cual 
da una idea de la importancia de este tema en el conjunto de la obra. La interpretación de Ochiai es que los dos mitos expresan la oposición binaria entre el bien y el mal, donde héroes y dioses son de entrada superiores a sus oponentes: "The enemies appear in the milieu of battle only to give the culture heroes an opportunity for victory" (p. 87). Al crear el desorden mediante el uso de la fuerza, héroes y dioses producen el orden en que se fundamentan sus acciones futuras y su misma existencia (p. 87). Ochiai dice que estos mitos reflejan la historia de la hegemonía epitolteca en el área del quiché, que fueron compuestos separadamente del resto del texto, pero con el mismo argumento y luego insertos en éste, y que los rige la explicación por medio de oposiciones (p. 95).

Materiales etnográficos recientes recopilados por Alain Breton entre los quiché-achí de Guatemala dan cuenta de un discurso ritual que expresa su dolor ante las masacres indígenas ocurridas en ese país en las últimas décadas, pero donde también se expresa la concepción cultural que tienen de esos acontecimientos y su determinación de superarlos, de vencer sobre el mal:

hubo abuelas y abuelos nuestros que fueron sacados de su hogar, que fueron sacados de su lecho. Que tengan culpa o que no tengan culpa, así fueron muertos ¡Ojalá que no lloren sus almas! ...Que vengan a juntarse [con nosotros] a gozar a saborear...(1989: 26).

El abundante material etnográfico sobre los mayas sugiere que muchos de los contenidos ideológicos de su antigua mitología continúan vivos en el pensamiento de los contemporáneos. Los choles de Chiapas, por cjemplo, cuentan un relato similar al del Popol Vuh, según el cual, en tiempos muy antiguos vivieron en la tierra una madre con dos hijos, pero estos últimos entraron en una relación de rivalidad; el hermano mayor odiaba al menor y trató de matarlo en varias ocasiones, sin conseguirlo. Pero al final el hermano menor triunfó sobre el otro, destruyéndolo y transformando sus restos en los animales del bosque, para luego subir al cielo junto con su madre y convertirse en el Sol y la Luna, respectivamente. 
Otros relatos choles, incluyendo aquellos sobre temas agrarios contemporáneos, dan cuenta de un pensamiento mitológico que reproduce aquel sentido arcaico de "vencer al enemigo" (Alejos, 1988).

\section{Discurso agrarista}

Sobre la época de la reforma agraria, los choles guardan muchos recuerdos y testimonios que conforman un género discursivo particular. Si bien la temática es de índole económica —el reparto de las tierras a los campesinos-, en el fondo los relatos agrarios incorporan las cuestiones mitológicas arriba señaladas.

Un tema específico de esa narrativa indígena es el fin de las grandes fincas cafetaleras alemanas y norteamericanas, que hasta la tercer década del presente siglo dominaron la agricultura del norte de Chiapas. La tradición oral cuenta que en aquella época, los campesinos eran esclavos de los finqueros y sus condiciones de vida eran terribles. Los relatos enfatizan la crueldad de los finqueros, los castigos que sufrían los peones por motivos de trabajo, o por los intentos de fugarse de la finca, que iban desde los azotes públicos, la cárcel, la fosa con hormigas, hasta la muerte.

Luego, la guerra "revolucionaria" es otro importante tema de esta narrativa. Los ancianos que la vivieron hablan de los enfrentamientos entre el ejército federal y los ejercitos de los finqueros, que concluyeron con la reforma agraria.

Mandaron a traer otro general pa' que nos venga a matar aquí $\mathrm{i}$ b bastantes murieron! Bastantes murieron, gentes, ¡los guindan! Así le echan un lacito así, mandan a traer, lo agarran, lo guindan allí, con cinco tiros todavía, así. ${ }^{1}$

Para los campesinos, aquellos fueron años de mucha pobreza y sufrimiento, que guardan en la memoria colectiva, pero también conservan la convicción de ser ellos quienes superaron tal situación mediante sus propias acciones. Hay relatos que narran la manera como los viejitos y un líder organizaron el movimiento agrario. Son ellos los héroes, los que idearon y llevaron a cabo la liberación campesina. Esta narrativa indígena encuentra su correlato en los documentos del archivo municipal,

${ }^{1}$ Comunicación personal con el señor Antonio Flores, del municipio de Tumbalá, en 1987 (cf. Alejos, 1994: 231 ss). 
donde aparece registrado ese proceso de reforma agraria, incluyendo un movimiento armado campesino, cuya intención, según los escritos, era "sublevarse" y "acabar con los ladinos".

Otro acontecimiento que destacan los relatos choles es la decadencia y ábandono de las fincas cafetaleras de la región. Un caso que ha quedado grabado en la memoria de los tumbaltecos es la suerte del alemán Federico Schilling, administrador de la finca El Triunfo, quien terminó por suicidarse ante el desplome de su empresa:

Mich'a cha'an ma'anix tak'in che' jini.

Estaba encolerizado por no tener dinero.

Tsi' letsa laso ti kukul i mil jats'ä i bä; chämi. [risas]

Subió un lazo a la viga y se ahorcó él mismo; así muri6. ${ }^{3}$

Este hecho, ocurrido en 1946, se encuentra documentado en las mismas fuentes de archivo (AMT, 739), y marca en el discurso campesino el punto culminante en que los finqueros son derrotados y los campesinos obtienen las tierras y la libertad.

$\mathrm{Al}$ igual que observamos en el discurso mitológico, un elemento fundamental de esta narrativa agrarista consiste en la superación de una situación inicial intolerable, que se logra mediante una transformación caracterizada por la lucha de los contrarios, la muerte del enemigo y el triunfo del bien sobre el mal. En un trabajo previo (1988) he mostrado la continuidad de algunas ideas y conceptos elementales de la narrativa chol; vemos que en el fondo existe una estructura binaria de significación que podría resumirse en la oposición vida/muerte. Los hombres indígenas no pueden vivir humanamente mientras exista un águila que los devore, animales del monte que destruyan sus cultivos, seres malignos que los engañen para matarlos y comer sus cuerpos, o finqueros que se hayan adueñado de las tierras, imposibilitando su vida autónoma y libre. Por eso mismo, la consecuencia lógica y el propósito que guía las acciones de los protagonistas es invertir dicha situación, es vencer al enemigo para restablecer así el orden de su mundo.

2 AMT, 711-730. Los documentos del archivo citados se encuentran publicados en Alejos y Ortega (1990), donde aparecen con la abreviatura AMT [Archivo Municipal de Tumbalá], seguida del número de su clasificación.

${ }^{3}$ Comunicación personal con el señor Francisco Arcos, Tumbalá, 1985 (cf. Alejos, 1994: 179). 


\section{La historia local}

En Chiapas han existido conflictos sociales desde la invasión española hasta la actualidad. En este apartado veremos algunos documentos del archivo tumbalteco sobre los años de la reforma agraria, con el fin de vincular estas fuentes históricas con los contenidos ideológicos de los mitos y de los relatos agraristas choles.

Tumbalá es un municipio del norte chiapaneco de tierras extremadamente montañosas, cubiertas hasta épocas recientes por un espeso bosque tropical y habitado casi en su totalidad por indígenas hablantes del idioma chol. Ellos son campesinos dedicados al cultivo de la milpa tradicional, y desde la reforma agraria son también pequeños productores de café; más recientemente también se ocupan a la crianza de ganado vacuno. Los pocos ladinos y descendientes de extranjeros viven sobre todo en el pueblo y en las fincas, antes cafetaleras y hoy ganaderas. Algunos de ellos se han enriquecido gracias al comercio de la producción campesina. El municipio se encuentra muy aislado por su accidentada geografía y por la falta de carreteras y otros medios de comunicación, aunque en los últimos años se ha desarrollado cierta infraestructura. Sus altitudes varían de los 300 a los $1600 \mathrm{~m}$ snm en un espacio de $705 \mathrm{~km}^{2}$.

$\mathrm{Al}$ igual que en otros municipios indígenas, en Tumbalá los choles viajan de un lugar a otro caminando por las veredas entre las montañas, distancias que pueden ser de dos y más horas de camino. El campesino siempre lleva un machete cuando sale al campo, pues es su principal instrumento de trabajo y a la vez un arma punzocortante. En su vida, enfrentar peligros, conflictos y la muerte misma, son hechos cotidianos y próximos, algo siempre presente, que los hace mantener determinadas actitudes y comportamientos. Aunque a primera vista las aldeas y pueblos indígenas puedan parecer tranquilos y pacíficos, en realidad también existen relaciones personales e intergrupales conflictivas y violentas.

Un anciano tumbalteco convertido al protestantismo, al contarnos su historia, opinaba que los campesinos habían cambiado mucho con "la llegada de la palabra de Dios", acontecimiento que coincide con la reforma agraria, ya que antes había muchas muertes:

¡Bastante! Mucho se mataban. 'Onde quiera lo oyes: que ya mataron allá, ya se mataron allá, 'onde quiera. Pero gracias a Dios, "ora ya entró la pala- 
bra de Dios... lo que es 'ora, ya están mansitos, ya puede uno andar a dondequiera, pero en aquel tiempo no se podía nada. ${ }^{4}$

Los documentos del archivo confirman que hace unos 70 años se vivía una profunda crisis social en la región. Una lista de individuos procesados por delitos cometidos en el entonces Departamento de Palenque (al cual pertenecían Tumbalá y otros municipios) entre 1924 y 1933 (AMT, 406) registra 23 procesados de Tumbalá ( $16 \%$ del total de 106 para todo el Departamento), de los cuales 18 fueron casos de homicidio. Hacia 1930, un censo del mismo municipio registró una población de 5832 habitantes, lo que da un promedio de dos homicidios por año y uno por por cada 3000 habitantes. Sin embargo, esas cifras no representan la situación real. Al comparar esa lista con otros documentos del mismo archivo, lo que queda de manifiesto es que la mayoría de estos quedaban impunes. Los casos de extrema violencia eran más frecuentes que los registrados como "procesados"; revisando el archivo de esos años, vemos que en aquel medio era fácil cometer homicidio y no ser procesado, o ser capturado y luego escapar. Por ejemplo, en 1925 se fugaron de la cárcel de Tumbalá dos homicidas del año anterior (AMT, 368) y dos años después se fugó el asesino de dos niños (AMT, 171). A esto habría que sumar las fugas ocurridas en la cárcel principal de Salto de Agua, que era donde se encerraba a los "procesados". 5

Entre los muchos casos registrados en las actas del juzgado de Tumbalá, cito tan sólo algunos que considero representativos de los conflictos sociales, ninguno de los cuales aparece registrado en la mencionada lista de procesados. En 1929 se registran tres agresiones contra las plantaciones de las fincas cafetaleras, causadas posiblemente por campesinos, la violación de una mujer indígena y la detención de su agresor, así como la captura de un presunto asesino. Un año particularmente conflictivo fue 1932, pues además del homicida procesado que registra la lista, aparece otro no capturado; hay dos actas sobre lesiones graves provocadas con machete y cuatro más sobre agresiones y robos. Además, ese mismo año, el archivo registra un importante movimiento campesino, del que se puede seguir su desarrollo desde finales de 1930 hasta inicios de 1932 (AMT, 712-730). El objetivo del movimiento era lograr la dotación de tierras ejidales y, con ello, la liberación del traba-

${ }^{4}$ Antonio Flores, en Alejos, 1994: 231 ss.

${ }^{5}$ Hay que hacer notar que los reos procesados eran una carga para el erario municipal, ya que mensualmente debía enviarse dinero para su mantenimiento a la cárcel de Salto de Agua. 
jo en las fincas. Los documentos señalan que entre las medidas para controlar la "sublevación", las autoridades capturaron a los líderes agraristas y decomisaron 74 escopetas. Sin embargo, a pesar de la oposición de los finqueros, al poco tiempo los objetivos campesinos empezaron a realizarse, al ser expropiados los latifundios y dar inicio el reparto agrario.

Aquel movimiento por la reforma agraria es toda una leyenda. En las aldeas se recuerda a los líderes agrarios como héroes que liberaron a su gente de la esclavitud, y el reparto agrario es visto como el resultado de esa lucha. En los relatos, pelear y dar muerte al agresor se percibe como un medio para la consecución del ulterior propósito de liberación y no como un crimen.

Así pues, las leyendas sobre los líderes agrarios son parte de un discurso social con lecciones densas, que prescriben qué hacer y se orientan a reproducir una visión del mundo y una conducta a seguir en relación con determinados asuntos. Si vencer es la intención de fondo, terminar con el mal es lo correcto.

Como señalé anteriormente, los libros de actas del juzgado municipal durante los años de la reforma agraria están llenos de casos de violencia extrema. En otra lista de procesados de Tumbalá entre 1936 y 1937 (Амт, 74) aparecen nueve casos, de los cuales cinco son homicidios. De nuevo, esa cifra sólo nos muestra que un número reducido de los casos eran procesados judicialmente. Suponiendo que dos años más tarde el número de procesados fuera similar, encontramos en las actas del juzgado de 193926 casos de lesionados con machete, 14 homicidios, dos suicidios y tres intentos de suicidio, mientras que las "diligencias penales", es decir averiguaciones y búsqueda de responsables de delitos fueron solamente tres. Según las estadísticas oficiales de población de 1940, Tumbalá contaba con 8673 habitantes (AMT, 334), lo cual nos da una tasa anual de un caso de extrema violencia por cada 192.7 habitantes. $^{6}$

Estas cifras son muy altas, si se comparan con las de un pueblo tzeltal (Teklum), estudiado por June Nash (1967) durante el periodo 19381965. La autora encuentra una tasa de 251.2 casos de homicidio por cada 100000 habitantes, que considera "fabulosamente alta", en relación con las tasas de México y de los Estados Unidos para 1964 (p. 456). Nash explica que el aumento en la tasa de homicidios en dicha población se debió a los procesos de cambio social, a la introducción de nuevas estructuras de poder y a la pérdida de las tradicionales (p. 469),

\footnotetext{
${ }^{6}$ Es posible que el número de casos haya sido aún mayor, pues la suma de actas del juzgado no coincide necesariamente con el total de hechos ocurridos.
} 
*

señalando que durante ese periodo, el homicidio era visto como una reacción a un crimen anterior y no como un crimen en sí mismo: "el homicidio es una solución aceptada en el conflicto interpersonal... es parte del patrón de expectativas del pueblo" (pp. 464, 468).

\section{$E l$ ethos indígena}

La antropología mesoamericana ha generado concepciones que al divulgarse y con el correr del tiempo se han convertido en asuntos de sentido común, en estereotipos que cobran un status de 'verdad' entre los investigadores y en la sociedad. Una de esas concepciones es la del carácter fatalista de las culturas indígenas, considerado como una esencia, como un arquetipo cultural, que rige la conducta y las ideas de los indígenas de ayer y hoy.

En un artículo sobre el "folklore narrativo" mesoamericano, Edmonson (1967) habla de un ethos indígena, un elemento distintivo de su cosmología y ética, que él caracteriza como un fatalismo trágico, contrastándolo con la filosofía optimista de Europa occidental. Ese fatalismo tendría sus bases en la concepción religiosa y en el calendario (p. 360 ), ya que según Edmonson, la literatura mesoamericana es eminentemente religiosa y "temáticamente preocupada por la fatalidad y la destrucción, la brujería y la calamidad, la conquista y la salvación" (p. 366). El autor vincula ese sentido trágico de la vida a la inmutabilidad del ciclo calendárico, donde el indígena no hace sino aceptar su trágico destino. Edmonson agrega que esa tradición es tan fuerte que ha permeado a la población no indígena (p. 359).

Otra versión acerca del fatalismo atribuido al pensamiento indígena se encuentra en Gossen (1974), quien cita a Geertz para afirmar que la tradición oral es un modelo del ethos comunitario y para él (p. XI). Cosmología y tradición oral son similares, pues ambas contienen el conocimiento público del orden. Gossen plantea que entre los chamulas de Chiapas, el sol es concebido como el principio rector de sus vidas, el sol es el gran ordenador, es Dios. Puesto que la tradición oral es un lenguaje normativo donde se encuentran codificados los conceptos religiosos y los modelos ideales de conducta e interacción (pp. 246, 248), es claro que aquí el Sol, por su carácter cíclico y "caliente", lo ordena todo, mientras que a los seres humanos no les queda sino subordinarse a sus designios.

En ambos casos se sostiene que el ethos del indígena mesoamericano es fatalista, es decir, basado en la doctrina según la cual los aconteci- 
mientos del mundo están predeterminados y el hombre no puede en esencia cambiar su rumbo. Esa visión trágica, negativa y triste, es contrastada por Edmonson con la visión feliz de Occidente.

Un tropos de ese ethos fatalista sería la muerte. En las creencias, actitudes, modalidades y, en general, en los significados atribuidos a la muerte, habría de manifestarse ese carácter trágico y pesimista del indígena. Pero, ¿son así realmente los indígenas mesoamericanos?, ¿es ése su ethos, su cualidad distintiva? Pienso que no, que el fatalismo, si bien puede estar presente, no es lo único, lo esencial ni lo más sobresaliente de su cultura. Además, considero que el ethos de un pueblo no está predeterminado por una sola idea o concepto, ni tampoco es estático, sino más bien es un producto histórico sujeto a cambios.

Los materiales que he discutido, así como una somera revisión de las publicaciones sobre mitología y literatura mesoamericana, en especial los textos que tratan de la lucha entre el bien y el mal, o los abundantes cuentos de animales, ${ }^{7}$ me llevan a reconocer en esa tradición indígena un gran espíritu de lucha, una actitud positiva por superar obstáculos y triunfar.

\section{Conclusiones}

Como he señalado respecto de la narrativa chol, lo distintivo de sus relatos es precisamente la idea de superar pruebas y obstáculos como el medio para la realización de los fines de los protagonistas. Con frecuencia esto se logra venciendo a la fuerza física por medio del truco, la astucia y el ingenio. En términos de Wittgenstein, esos relatos conforman un juego de lenguaje particular, expresan una forma de vida, cuya lógica radica en vencer para lograr los objetivos humanos y para restablecer el orden del mundo. Así, vemos cómo detrás de los relatos agraristas de los choles, en su concepción de los acontecimientos del pasado, hay una intencionalidad, una lectura ideológica de los hechos, vinculada a otros géneros discursivos. Con una visión realista de la vida, muy ligada a su entorno natural y social, los choles dicen cómo invertir una situación considerada intolerable, infrahumana, contraria

${ }^{7}$ Según Edmonson, en Mesoamérica "hubo poco desarrollo de ciclos de cuentos relacionados, centrados en el carácter de un héroe particular" (1967: 360). Pero basta con considerar los cuentos de animales como el jaguar, el conejo, el coyote o el tlacuache, para reconocer la rica narrativa sobre héroes culturales personificados en animales. 
a su vida. El movimiento es dialéctico, en tanto que de las contradicciones surge algo nuevo y bueno para el hombre.

Por otro lado, los choles, al igual que muchos otros de sus hermanos mesoamericanos, han vivido una realidad brutal y miserable, dentro de un sistema social opresivo y cruel. De allí que sus respuestas sean de lucha, contestatarias, violentas. En este sentido, puede decirse que la tradición oral indígena es un testimonio de la condición social de sus portadores. Sus mitos, leyendas, fábulas, todo está cargado de pasado histórico y proyecta la imagen de una gente que, lejos de ser fatalista, es ingeniosa, enérgica y luchadora. La historia da cuenta de un pueblo que no está dispuesto a aceptar pasivamente una realidad adversa.

Darnton (1987) afirma que los cuentos son documentos históricos que han cambiado con el tiempo, adoptando diferentes formas en distintas tradiciones culturales y enraizados en la vida real de su época. Argumenta que los llamados cuentos maravillosos de Europa occidental del siglo xviII no proyectaban una visión feliz, sino que, por el contrario, reproducían la vida miserable de los campesinos que los contaban,

Los campesinos de los albores de la Francia moderna habitaban un mundo de madrastras y huérfanos, de trabajo cruel e interminable, y de emociones brutales, crudas y reprimidas... gente cuya vida realmente era sórdida, brutal y breve (p. 36).

$\mathrm{Al}$ mostrar cómo era la vida, terre à terre, en las villas y en los caminos, los cuentos ayudaban a los campesinos a orientarse. Mostraban el comportamiento del mundo y la locura de esperar algo que no fuera crueldad de un orden social cruel (p. 46).

La época a la que corresponde la documentación que hemos discutido se caracterizó por la violencia extrema, fue el clímax y ruptura de una estructura agraria latifundista. Los campesinos se encontraban en pie de guerra y esto se evidencia en la violencia en su sociedad y en contra de los finqueros y de los kaxlanes en general. Era, pues, un momento en que los choles veían llegada la hora de la justicia, de la recuperación de lo propio. Al hacer la comparación de esto con la tradición oral, en especial con los mitos antiguos, vemos que según el modelo paradigmático, en tales situaciones, así debe actuarse.

Existen, pues, nexos muy íntimos entre la tradición oral de un pueblo y su realidad social concreta. Los mitos encuentran sus referentes en las relaciones sociales, aunque los vínculos no son visibles, direc- 
tos o inmediatos, y lo uno no es un mero reflejo de lo otro. Los mitos poseen su propia dimensión, pero se plasman en la realidad, en la conducta de los individuos en sociedad. Por eso, en los mitos choles, la opresión, la lucha y el triunfo son componentes de un discurso cuyo sentido se encuentra en la vida real y cotidiana.

\section{Bibliografia}

Alejos García, José

1988 Wajalix bä t'an. Narrativa tradicional chol de Tumbalá, UNAM, Chiapas, México.

1994 Mosojäntel. Etnografía del discurso agrarista entre los choles de Chiapas, unam, México.

Alejos Garcia, José, y Elsa Ortega Peña

1990 El Archivo Municipal de Tumbalá, Chiapas, 1920-1946, UNAM, México.

BAJTí, Mijaíl

1982 Estética de la creación verbal, Siglo XXI, México, pp. 248293.

BRETON, Alain

1989 'El ‘Complejo Ajaw' y el 'Complejo Mam'. Actores rituales y héroes míticos entre los Quiché-Achí de Rabinal (Baja Verapaz, Guatemala)", Memorias del II Coloquio Internacional de Mayistas, UNAM, México, vol. 1, pp. 17-27.

DARNTON, Robert

1987 La gran matanza de los gatos y otros episodios de la historia de la cultura francesa, Fondo de Cultura Económica, México.

Edmonson, Munro

1967 "Narrative Folklore", Handbook of Middle American Indians, Texas University Press, Austin, vol. 6, pp. 357-368.

Gossen, Gary

1974 Chamulas in the World of the Sun, Harvard University Press, Cambridge.

Lévi-Strauss, Claude

1983 Antropología estructural, Siglo XXI, México.

NASH, June

1967 "Death as a Way of Life: The Increasing Resort to Homicide in a Maya Indian Community", American Anthropologist, 69, pp. 455-470. 
OchIAI, Kazuyasu

1986 "On Whom the Gods Tried Their Swords: A Semiotic Approach to the Combat Myths of the Popol Vuh", en G. Gossen (editor), Symbol and Meaning Beyond the Closed Community, Albany, pp. 83-100.

\section{Popol Vuh}

1982 Adrián Recinos (editor), Fondo de Cultura Económica, México.

Ruz LhuILlier, Alberto

1991 Costumbres funerarias de los antiguos mayas, unam, México.

WITTGENSTEIN, Ludwig

1968 Philosophical investigations, The Macmillan Co., Nueva York. 